\title{
Is an Antiplatelet Treatment required after an Endovascular covered stent placement for Treatment of Iatrogenically Injured non diseased Arteries?
}

\author{
Abhijit L Salaskar* and Michael H Hamblin \\ Department of Interventional radiology, Presence Saint Francis Hospital, USA
}

Submission: August 15, 2018; Published: August 27, 2018

*Corresponding author: Abhijit L Salaskar, Department of Interventional radiology, Presence Saint Francis Hospital, Evanston, IL 60626, Email: abhijitlausalaskar55@gmail.com

Keywords: Arterial injury; Iatrogenic vascular injury; Covered stent; Antiplatelet treatment

Abbreviations: R-CCA: Right Common Carotid Artery; SFA: Superficial Femoral Artery; CVC: Central Venous Catheter

\section{Opinion}

The patient was a 50-year-old female who had past medical history of hemiglossectomy for squamous cell carcinoma of tongue and recent diagnosis of lung metastasis now presented to emergency department with respiratory failure and sepsis. During resuscitation, CVC was erroneously placed into a R-CCA. CT scan of the neck revealed a CVC entering from right side of the neck then coursing directly into the R-CCA lumen. Patient was urgently taken to IR suite. Selective angiography demonstrated patent R-CCA without any extravasation and 7 Fr CVC entering into the lumen of R-CCA and then coursing into the aortic arch. Under fluoroscopy guidance, as the CVC was slowly being retracted over a wire, a $7 \mathrm{~mm} \times 2.5 \mathrm{~cm}$ heparin bonded Viabahn covered stent was deployed to seal the defect in the R-CCA. The stent was then inflated with same size $7 \mathrm{~mm}$ balloon without exerting any stretch on the vessel wall. Completion angiography demonstrated patent R-CCA without any evidence of extravasation. Based on prior CT scans, patient did not have any atherosclerotic disease in the cardiovascular system. After carotid artery stenting, patient was placed on antiplatelet medication regimen with an intention to prevent a stent thrombosis as per the common clinical practices. However, we would like to question the need for any antiplatelet treatment after an endovascular stent placement for the treatment of iatrogenically injured non-atherosclerotic disease-free vessel.

There has never been any consensus about optimal type and duration of antiplatelet/anticoagulation regimen after an endovascular stenting of carotid artery stenosis or peripheral arterial disease. The prescribing practices of antiplatelet agents after endovascular stenting of carotid or peripheral arteries are primarily influenced by the data in percutaneous coronary intervention studies [1,2]. In coronary intervention studies, prolonged degree of platelet activation was seen after stenting the diseased coronary vessels as opposed to angioplasty alone. These studies used bare metal stents which were prone to develop stent thrombosis especially in the presence of underlying atherosclerosis [3,4]. Another prospective randomized study concluded that the platelet activation plays a key role in the pathogenesis of stent occlusion and embolic complications and hence dual antiplatelet regimen has a significant impact on reduction of adverse neurological outcomes [1]. However, in this study, bare metal stents acted as a nidus for platelet activation, neointimal hyperplasia and luminal in growth of thrombus in the presence of underlying atherosclerosis. The results of this and few prior studies cannot be extrapolated for prescribing antiplatelet medications after endovascular stenting of iatrogenically injured non-diseased arteries.

Another animal study indicated that use of slow expanding stents in comparison to high force angioplasty efforts had lesser degree of arterial wall injury and thus reduced incidence of diseased vessel restenosis. However, during endovascular stenting of iatrogenically injured non-diseased arteries, arterial lumen expansion is not attempted as in the management of our patient [5].

In the prior studies, latest generation heparin bonded Viabahn stents have shown significant patency benefits in comparison to bare metal stents at 24 months. Also, three-year patency rates of new generation Viabahn stent which were used for sSFA occlusive disease, were reported to be comparable to surgical reconstruction [6]. Successful results of these studies were attributed to the ability 
of new generation covered stents to prevent local remodeling, neointimal hyperplasia, and luminal in-growth. Patients included in these studies had atherosclerotic occlusive disease and were also placed on antiplatelet medications after endovascular stenting. Use of post stenting antiplatelet medications in these studies theoretically may have contributed in part to the patency benefit by preventing anticipated stenosis at the end of covered stents, especially in the setting of underlying atherosclerotic disease. However, there is no prior study comparing patency outcomes between a group who had taken antiplatelet medication after covered stent placements and a group who did not take an antiplatelet medication after the placement of covered stent. Also, latest generation Viabahn stents have reshaped edges to prevent in folding of vessel wall and thrombosis at the ends of stents. In our opinion anticipation of stenosis at the end of covered stents could be appropriate in the setting of underlying atherosclerotic disease. However, in the absence of underlying atherosclerosis, after an iatrogenic arterial injury such as in our patient, the incidence of thrombosis of new generation covered stents may be significantly low. Hence is there a need for antiplatelet treatment after an endovascular covered stent placement for the treatment of iatrogenically injured disease- free vessel?

\section{References}

1. McKevitt FM, Randall MS, Cleveland TJ, Gaines PA, Tan KT, et al. (2005) The benefits of combined anti-platelet treatment in carotid artery stenting. Eur J Vasc Endovasc Surg 29(5): 522-527.

2. Allemang MT, Rajani RR, Nelson PR, Hingorani A, Kashyap VS (2013) Prescribing patterns of antiplatelet agents are highly variable after lower extremity endovascular procedures. Ann Vasc Surg 27(1): 62-67.

3. Gawaz M, Neumann FJ, Ott I, May A, Rüdiger S, et al. (1996) Changes in membrane glycoproteins of circulating platelets after coronary stent implantation Heart 76(2): 166-172.

4. Parsson H, Cwikiel W, Johansson K, Swartbol P, Norgren L (1994) Deposition of platelets and neutrophils in porcine iliac arteries after angioplasty and wallstent placement compared with angioplasty alone. Cardiovasc Intervent Radiol 17(4): 190-196.

5. Schwartz RS (1998) Pathophysiology of restenosis: Interaction of Thrombosis, Hyperplasia, and/or remodeling. Am J Cardiol 81(7A): 14E-17E.

6. Lammer J, Zeller T, Hausegger KA, Schaefer PJ, Gschwendtner M, et al (2013) Heparin-bonded covered stents versus bare-metal stents for complex femoropopliteal artery lesions: randomized VIASTAR trial. J Am Coll Cardiol 62(15): 1320-1327.

\begin{tabular}{|l|}
\hline \multicolumn{1}{|c|}{ Your next submission with Juniper Publishers } \\
will reach you the below assets \\
- Quality Editorial service \\
- Swift Peer Review \\
- Reprints availability \\
- E-prints Service \\
- Manuscript Podcast for convenient understanding \\
- Global attainment for your research \\
- Manuscript accessibility in different formats \\
( Pdf, E-pub, Full Text, Audio) \\
- Unceasing customer service \\
Track the below URL for one-step submission \\
https://juniperpublishers.com/online-submission.php \\
\hline
\end{tabular}

